e-ISSN: 2359-5078

\title{
Diagnóstico da evasão em cursos de educação profissional por intermédio do Projeto Político Pedagógico
}

Diagnosis of evasion in professional education courses through the Pedagogical Political Project

\author{
Rodolfo Gabriel Deganut ${ }^{1 *}$; Tatiane da Silva ${ }^{2}$
} ${ }^{1 *}$ Senac São Paulo. Especialista em Gestão Escolar pela Universidade de São Paulo e Graduado em Licenciatura em Pedagogia pela Universidade Cidade de São Paulo -
Avenida Conselheiro Nébias, 309 - Vila Mathias - 11015-003 - Santos, SP - Brasil < rodolf_gd@ hotmail.com>

${ }^{2}$ Universidade Estadual Paulista "Júlio de Mesquita Filho" [UNESP]. Dra. Educação Escolar - Rodovia Araraquara, Km 1 - Jaú - $14.800-901$ - Araraquara, SP - Brasil

\section{Resumo}

Abandonar a própria qualificação profissional é acabar com perspectivas de inserção no mercado de trabalho ou ainda interromper o próprio crescimento profissional. Diagnosticar e combater a evasão são ações que requerem a participação de todos os agentes escolares. Tendo em vista esse pressuposto, o objetivo deste trabalho consistiu na elaboração, por meio do Projeto Político Pedagógico, de ferramentas auxiliadoras que possam estimular a permanência dos alunos em uma instituição que promove cursos de capacitação profissional. Por intermédio de revisões bibliográficas e de aplicação de questionários com alunos que solicitaram o cancelamento de sua matrícula, bem como com docentes, coordenação e supervisão escolar, foi possível estabelecer alguns dos fatores preponderantes que estão relacionados à evasão escolar da instituição de ensino foco da pesquisa. Os resultados indicam que aproximadamente $50 \%$ dos alunos que se matriculam no ensino profissional realizaram o cancelamento de sua matrícula, justificado por dois tipos de fatores, internos e externos à escola, mas que em ambos os motivos se constatou que o colégio pode contribuir na promoção de meios que efetivem a profissionalização e conclusão do aluno no curso escolhido. O estreitamento de relações entre educandos e agentes escolares, priorizando o diálogo e estabelecendo estruturas favoráveis a permanência do aluno, é um dos conceitos básicos do Projeto Político Pedagógico, que elaborado coletivamente, resulta em uma escola colaborativa e acessível à comunidade, diminuindo assim a evasão dos alunos.

Palavras-chave: alunos evadidos, pgestão escolar, permanência na escola, resgate do aluno

\begin{abstract}
When a student leaves a professional qualification course is ending up with prospects of insertion in the employment market or still interrupting his/her own professional growth. Diagnosing and combating evasion are actions that require the participation of all school agents. In the light of this assumption, this academic work aims to develop auxiliary tools that can encourage the permanence of the students in an institution that promotes professional qualification courses by the Pedagogical Political Project. Through bibliographic reviews and application of questionnaires with students who requested the cancellation of their enrollment, as well as with teachers, school coordination and scholar supervision, it was possible to establish some of the preponderant factors that are related to school dropout at the research institution - focus of the research. The results indicates that approximately $50 \%$ of the students enrolled in professional qualification courses canceled their enrollment, justified by two types of factors, internal and external to the school, but in both cases it was found that the school can contribute to the promotion of means that effect the student's professionalization and completion in the chosen course. Building close relationship between students and school agents, prioritizing dialogue and establishing favorable structures to the student's permanence, is one of the basic concepts of the Pedagogical Political Project, which is produced collectively, results in a collaborative school, accessible to the community, thus reducing student evasion.
\end{abstract}

Keywords: evaded students, school management, permanence in school, student rescue

\section{Introdução}

O Projeto Político Pedagógico [PPP] é um dos principais documentos que orientam o processo educacional. Transpondo os limites de sua obrigatoriedade firmada pelo artigo 12 da Lei de Diretrizes e Bases [LDB] a qual estabelece que as instituições de ensino, resguardadas suas normas comuns e as do seu sistema de ensino, deverão se incumbir pela elaboração e execução de sua proposta pedagógica, o PPP pode ser considerado um documento com propostas e ações que devem ser vivenciadas pela equipe e a comunidade escolar de forma significativa (Brasil, 1996). 
O PPP conta a história da instituição de ensino, apresentando também o seu perfil atual e definindo metas para seu desenvolvimento. Segundo Pimenta (1993), o projeto pedagógico pode ser considerado a leitura que a escola faz de suas finalidades, partindo das necessidades que se evidenciam com a comunidade escolar, professores, alunos, equipe pedagógica e pais e a partir dos recursos que dispõe.

Ao buscar a definição das palavras "projeto", "político" e "pedagógico" desvelam-se respectivamente o sentido de intencionalidade, foco, a relação do homem com ideologias e a função formadora da sociedade; nas palavras de Veiga (1998) o projeto é uma ação que busca um rumo, direciona, e ao ser definido coletivamente e estabelecido por meio de interesses coletivos transforma-o em um ato político e pedagógico por estar vinculada a ele a ação formadora para a sociedade.

Para que as ações imbuídas na proposta do projeto sejam desempenhadas com qualidade e atinjam o foco do PPP, é necessário que todos entendam que a natureza desse documento é transmutável e temporal, pois poderá ser necessário realizar adaptações quando for preciso, mesmo após sua elaboração, para a concretização de suas metas. Para Pimenta (1993) o projeto não está pronto, mas em construção, sendo assim, a todo o momento a equipe vai depurando, explicitando, detalhando a inserção da escola na transformação social.

Ao parafrasear as metas que o Projeto Político Pedagógico pode conter, é possível discorrer sobre diversos temas como o desenvolvimento de competências em seus educandos e/ou educadores, em métodos de integração da comunidade junto à escola, a proposta de uma educação futura ou ainda na identificação de problemas a serem sanados, além de muitos outros assuntos.

Como visto anteriormente, uma das metas do PPP é a identificação de problemas que a instituição de ensino possa ter e a partir dessa constatação, planejar ações que solucionem a dificuldade ou que pelo menos ajude a atenuá-la. É importante frisar que a evasão escolar pode ser considerada um problema que assola a maioria das unidades de ensino (Queiroz, 2002). Definida enquanto abandono da escola pelo aluno, a evasão escolar é, ao lado da repetência, uma das principais dificuldades enfrentadas pela educação brasileira (Menezes e Santos, 2001). Para combater a evasão escolar é fundamental diagnosticar suas causas e buscar as possíveis soluções, com o objetivo de possibilitar o retorno efetivo do aluno à escola e/ou a sua permanência (Campos e Santana, 2013).

Para a educação profissional o fenômeno da evasão não se diferencia dos demais níveis de ensino. Entretanto, no Brasil, não existem muitos estudos sobre esse tema, diferentemente do que ocorre em outros países do mundo nos quais esse assunto é estudo bastante frequente (Cravo, 2012). Quando se propõe a ampliação das vagas para o acesso ao ensino técnico é essencial também que sejam consideradas situações e propostas que fortaleçam a permanência e o desempenho acadêmico do educando, proporcionando de forma efetiva a qualificação profissional e social desse aluno (Meira, 2015). Esse nível de ensino, assim como o ensino superior, é considerado opcional aos educandos, o qual apenas os que possuem interesse em seu desenvolvimento acadêmico/profissional o buscam. Porém, nem mesmo o fator interesse evita o alto índice de seu abandono.

O entendimento de educação profissional vem dos tempos mais remotos, o qual sempre foi necessário transmitir o conhecimento e desenvolver habilidades para garantir o exercício de um ofício. No Brasil colônia, a formação dos indivíduos era encarada de forma dualista, uma voltada para o aprendizado de trabalhos manuais ou os ditos ofícios para a classe desfavorecida como índios e escravos, com funções consideradas indignas, e outra para a elite, de forma propedêutica com um caráter acadêmico (Vieira e Souza Junior, 2016). Hoje este segmento de ensino, antes voltado mais para a formação do trabalhador manual, é definido como Educação Profissional e Tecnológica, por qualificar o educando a atuar no mercado de trabalho.

Partindo dos pressupostos anteriormente apresentados, o objetivo deste trabalho foi investigar a respeito das principais causas de evasão em um curso profissionalizante almejando com esse diagnóstico a projeção e elaboração de medidas e ações por intermédio do Projeto Político Pedagógico para combater o abandono dos cursos pelos alunos e garantir a permanência dos estudantes até a obtenção do certificado.

\section{Metodologia}

A pesquisa atentou-se com fatores da realidade, centrando na compreensão e explicação das relações sociais, podendo ser definida como qualitativa (Gerhardt e Silveira 2009). Entretanto, também se utilizou de dados quantitativos para efetuar interpretações acerca do fenômeno estudado. A pesquisa foi fundamentada por intermédio de leituras bibliográficas relacionadas ao PPP e ao estudo da evasão escolar, por meio de periódicos, dissertações e livros, além da aplicação de questionários com educandos que solicitaram cancelamento de sua matrícula e com a equipe pedagógica da escola analisada, dentre esses, professores, coordenadores de cursos e supervisor educacional. Para um entendimento mais amplo do fenômeno também se analisou os documentos da escola, especialmente as matrículas efetuadas no ano de 2016.

Para a realização da pesquisa, foram utilizados questionários acompanhados primeiramente pela apresentação do Termo de Consentimento Livre e 
Esclarecido confeccionado em conformidade com as instruções do Comitê Ético de Pesquisa ao qual este trabalho está subordinado. Foram aplicados questionários com 16 alunos evadidos, com sete professores, um coordenador e um supervisor educacional, todos atuantes na escola lócus da pesquisa.

Tais questionários continham questões de identificação das características pessoais do educando, a forma de subsídio utilizada para custear seus estudos, os motivos que o levaram a buscar a profissionalização formal e as causas que culminaram na solicitação de cancelamento e ações sugeridas que a instituição poderia proporcionar para a sua permanência no curso. Para o corpo técnico do quadro escolar o questionário identifica o tempo que leciona, a formação, e situações de quando o aluno aborda sobre a possível evasão, quais as ferramentas utilizadas para promover a continuidade no curso, o que poderia ser melhorado no colégio para atender o aluno e ainda a participação do planejamento dos cursos, com o intuito de diagnosticar se as necessidades dos alunos eram levadas em consideração no planejamento. Ambos questionários possuíam questões com respostas abertas e fechadas que objetivavam a identificação dos motivos, internos e externos à escola, que levaram à evasão escolar em cursos de qualificação profissional, buscando suporte para propostas e ações a serem aplicadas para a permanência do aluno até a conclusão do curso. Dessa maneira, o presente estudo é considerado de natureza aplicada e objetivo exploratório, por almejar a obtenção de informações com a realidade local, originando conhecimento e conduzindo a solução do problema estudado (Gerhardt e Silveira, 2009).

A Instituição de Ensino que se constituiu no objeto desta pesquisa está localizada na cidade de Santos, Litoral Sul do Estado de São Paulo. A escola atende alunos da região metropolitana de Santos, contando com estudantes provenientes de Bertioga à Peruíbe. Ela oferece cursos de formação inicial, continuada e subsequente, nas áreas de saúde e bem-estar, estética e beleza, meio ambiente, segurança e saúde no trabalho, tecnologia da informação, arquitetura e urbanismo, eventos e lazer, gastronomia, gestão e negócios e comunicação e artes. E possui, ainda, autonomia para determinar os horários de realização de seus cursos, bem como a definição do calendário escolar. Os cursos de nível técnico, no período da manhã, são ministrados das $08 \mathrm{~h} 00 \mathrm{~min}$ às $12 \mathrm{~h} 00 \mathrm{~min}$; tarde, das $14 \mathrm{~h} 00 \mathrm{~min}$ às $18 \mathrm{~h} 00 \mathrm{~min}$ (cursos que utilizam laboratórios que necessitam de assepsia terminam às $17 \mathrm{~h} 30 \mathrm{~min}$ ), e no período da noite, das $19 \mathrm{~h} 00 \mathrm{~min}$ às $22 \mathrm{~h} 30 \mathrm{~min}$ (cursos da área de informática iniciam às 19h30min). Eles ocorrem de segunda à sexta-feira (cursos na área de design e teatro possuem também cursos oferecidos de segunda, quarta e sexta-feira).

\section{Resultados e Discussão}

Conforme dados coletados na pesquisa documental junto à escola, em 2016, houve 1056 matrículas em 34 turmas de cursos técnicos que iniciaram entre janeiro e dezembro do mesmo ano.

Pode-se comparar a quantidade de matrículas entre os sexos feminino e masculino por meio da Figura 1, revelando que as mulheres predominaram na busca por qualificação profissional totalizando 702 (66,5\%) matrículas contra 354 (33,5\%) do público masculino.

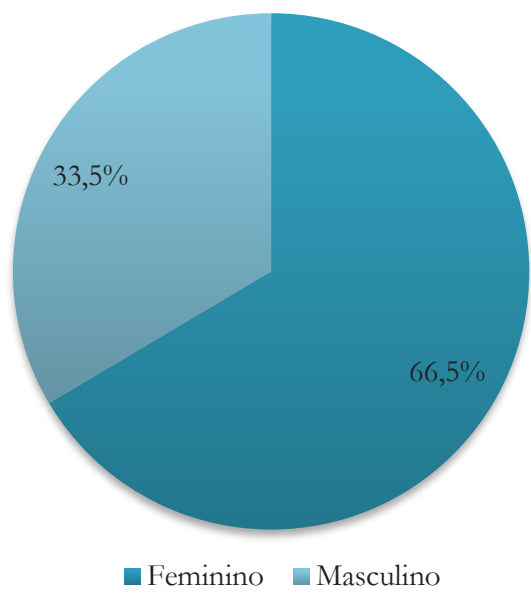

Figura 1. Quantidade de matrículas distribuídas por sexo no ano de 2016

As 23 turmas com início em 2016 e que permaneceram em curso tiveram um total de 724 matrículas (Figura 2). Desse total, apenas 349 (48,2\%) alunos ainda estavam ativos; 289 (39,9\%) alunos evadidos e ainda houve $86(11,9 \%)$ alunos desistentes. De acordo com esses dados, pode-se perceber que a somatória do número de alunos evadidos e desistentes foi maior que o número de alunos ainda em curso (Figura 2). Deve-se destacar que foram utilizadas as palavras "Desistentes" para classificar os alunos que realizaram sua matrícula, porém não frequentaram as aulas ou então que solicitaram cancelamento de sua matrícula antes do início do curso; "Evadidos" para nomear os alunos que iniciaram o curso e interromperam seus estudos, pedindo o cancelamento do curso depois de efetivarem a matrícula e frequentarem as aulas; "Reprovados" para os alunos que cursaram do início ao fim, porém não cumpriram com os critérios para aprovação; "Aprovados" para os alunos que frequentaram o curso do início ao fim e cumpriram os critérios de aprovação da escola; e "Em curso" para os alunos regularmente matriculados e ainda frequentes uma vez que o curso não tenha chegado ao seu fim. 


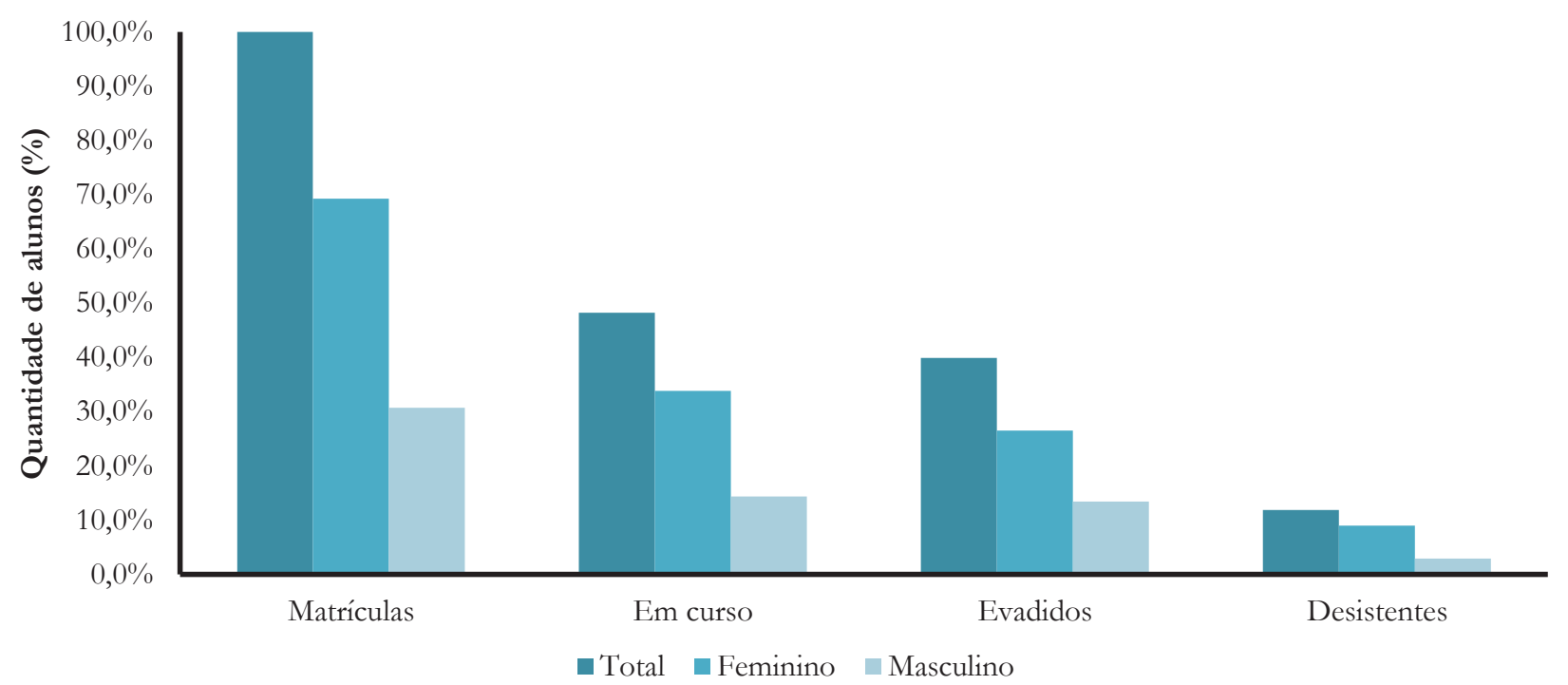

Figura 2. Número de matrículas no ano de 2016 distribuídas entre alunos em curso, evadidos e desistentes

Analisando as 11 turmas que iniciaram em 2016 com 332 alunos, mas já concluídas, que tiveram seu término entre 2017 e início de 2018, a quantidade de alunos que cursaram até o final do curso, entre os aprovados e reprovados consiste em 164 (49,4\%) educandos, enquanto que para alunos evadidos e desistentes houve $168(50,6 \%)$. Estes dados podem ser apreciados na Tabela 1.

Tabela 1. Número de matrículas distribuídas com resultado final, após conclusão do curso, entre alunos aprovados, reprovados, evadidos e desistentes

\begin{tabular}{|c|c|c|c|}
\hline \multirow{2}{*}{$\begin{array}{l}\text { Resultado } \\
\text { Final }\end{array}$} & \multicolumn{2}{|c|}{ Sexo } & \multirow{2}{*}{$\begin{array}{l}\text { Total de } \\
\text { Alunos }\end{array}$} \\
\hline & Feminino & Masculino & \\
\hline & & ----- \% ----- & \\
\hline Evadidos & 24,7 & 14,5 & 39,2 \\
\hline Desistentes & 6,3 & 5,1 & 11,4 \\
\hline Reprovados & 8,1 & 3,9 & 12,0 \\
\hline Aprovados & 21,1 & 16,3 & 37,4 \\
\hline
\end{tabular}

A Figura 3 apresenta dados dos resultados obtidos ao se analisar apenas as matrículas do sexo feminino distribuídas nas 23 turmas iniciadas no ano de 2016. Destacou-se que a evasão e desistência, se somadas $(51,3 \%)$, foram maiores que a quantidade de alunas consideradas aprovadas, reprovadas e em curso $(48,7 \%)$, juntas.

Os dados da Figura 4 evidenciaram a classificação dos alunos do sexo masculino, também considerando as 23 turmas iniciadas em 2016. Ressaltou-se, assim como na Figura 3, o número significativo de alunos evadidos e desistentes $(51,7 \%)$ em relação aos alunos em curso, aprovados e reprovados $(48,3 \%)$.

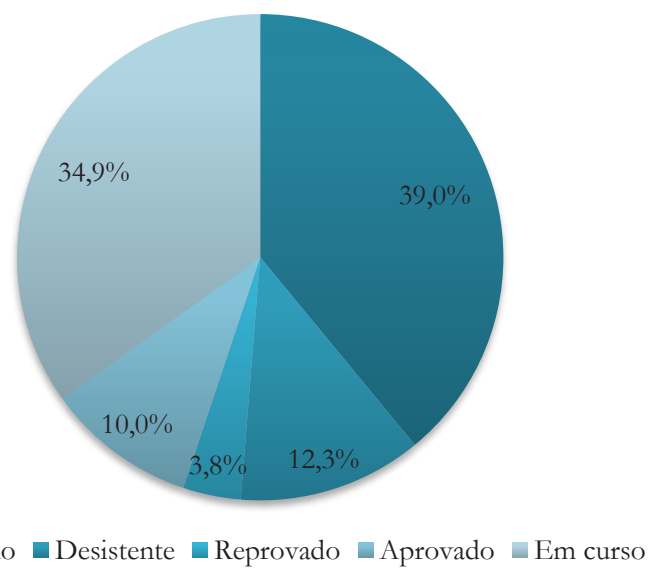

Figura 3. Classificação dos alunos considerando apenas o sexo feminino

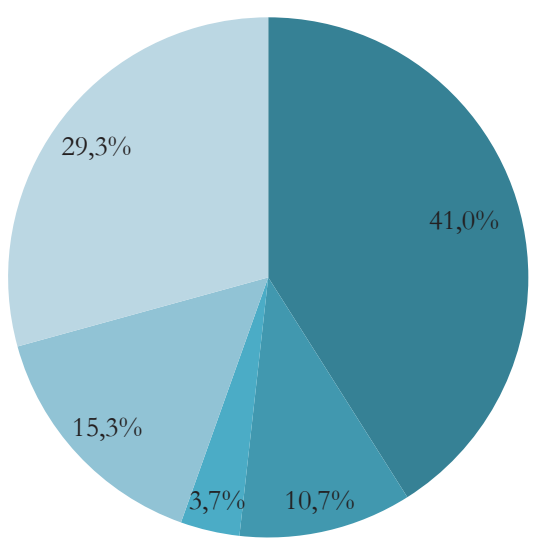

Evadido $\square$ Desistente $\square$ Reprovado $\square$ Aprovado $\square$ Em curso

Figura 4. Classificação dos alunos considerando apenas o sexo masculino 


\section{Projeto Político Pedagógico da Escola}

Ao proceder-se a análise dos documentos escolares foi constatado que a escola não desenvolveu seu PPP, porém, as gerências administrativas da rede de ensino começaram a incentivar a elaboração do documento, com manuais orientadores, vídeos esclarecedores e grupos de suporte.

É importante ressaltar que, apesar da ausência do PPP, a rede de ensino possui Missão, Valores e Proposta Pedagógica comum a todas as unidades e que preveem Projetos Ambientais, Educação do Futuro, Projeto Escola da Ponte, a serem desenvolvidos localmente, e com compartilhamento de seus desenvolvimentos com outras unidades. Além desses projetos, há ainda encontros de capacitação de docentes e funcionários, alguns comuns a rede e outros específicos, elaborados especialmente para a unidade. Entretanto, deve-se destacar a necessidade da elaboração do PPP e sua real concretização na dinâmica interna da escola, no real, no concreto (Veiga, 1995).

Os princípios orientadores essenciais para o desenvolvimento e implementação do PPP, conforme apontado por Veiga (1995) são: a igualdade de condições para acesso e permanência na escola, assim como a manutenção da igualdade e da qualidade na consecução dos objetivos por parte da escola e dos alunos; a gestão democrática, centralizando questões pedagógicas, administrativas e financeiras na própria escola. Outro princípio orientador apontado pela autora e que interessa de maneira direta a esta pesquisa refere-se ao enfrentamento de problemas de exclusão e reprovação e da não permanência do aluno na sala de aula; é tendo esse princípio como base que se pauta a discussão a seguir.

\section{A Evasão da Perspectiva dos Educandos}

Para o aprofundamento da questão que norteou esta pesquisa, buscou-se a aplicação do questionário com alguns alunos que procuraram a escola e solicitaram o cancelamento de sua matrícula no mês de fevereiro de 2018. O total de respondentes foram 16 alunos, com idades que variavam entre 18 a 86 anos. Foi identificado também que 12 (75\%) educandos que solicitaram o cancelamento, estavam na faixa etária de 21 a 40 anos de idade, conforme Tabela 2.

Tabela 2. Classificação etária dos alunos que solicitaram cancelamento considerando ambos os sexos

\begin{tabular}{lrrr}
\hline \multirow{2}{*}{ Faixa Etária } & \multicolumn{2}{c}{ Sexo } & Total de \\
& Feminino & Masculino & Alunos \\
\hline \multirow{3}{*}{ 15 a 20 anos } & 6,2 & $---\%$-- & \\
21 a 30 anos & 25,0 & 19,0 & 44,4 \\
31 a 40 anos & 25,0 & 6,2 & 31,2 \\
A partir de 41 anos & 6,2 & 6,2 & 12,4 \\
\hline
\end{tabular}

Conforme constatado pelos dados coletados do ano de 2016 e somando à análise da Figura 5, evidenciou que 10 alunos que participaram da pesquisa, foram do sexo feminino. E, em seu total, 15 educandos realizavam ou realizariam o curso nos períodos da manhã e/ou da noite, apenas um no período da tarde, sendo que a preferência em estudar nos períodos da extremidade pode ser devido à carga horária de trabalho. Quanto ao investimento na profissionalização, os resultados mostraram que nove dos alunos custearam as despesas do curso por meio de suas rendas, enquanto apenas um possui incentivo financeiro da empresa em que trabalha; quatro receberam bolsa de estudos integral por intermédio da instituição e dois contaram com auxílio financeiro de familiares para sua capacitação.

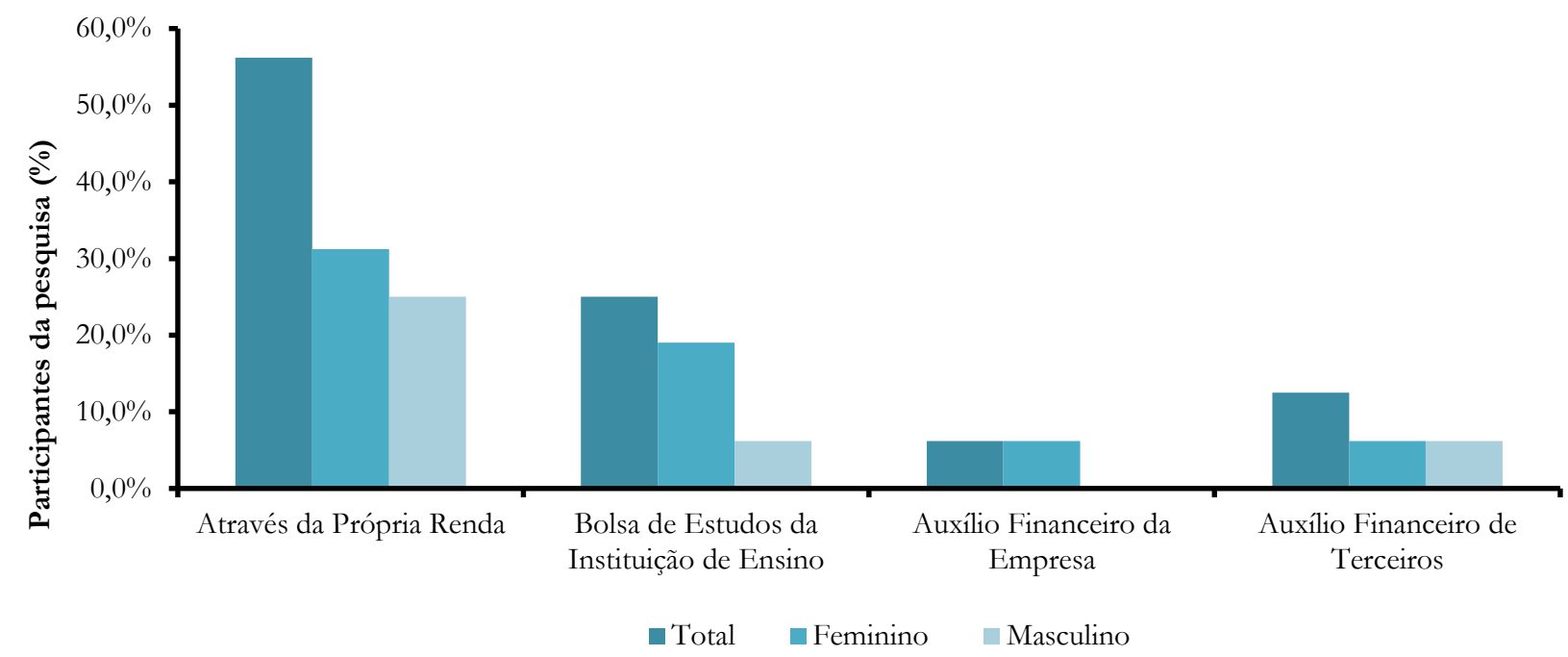

Figura 5. Classificação da origem do investimento na educação no ano de 2016 
Dos participantes da pesquisa, nove alunos apontam que os principais motivos para a busca de sua formação profissional são devido ao fato de trabalharem na área. Enquanto que cinco respondentes indicam a necessidade de melhorar sua posição no mercado trabalho, para identificar com mais clareza os motivos da qualificação profissional, o público pesquisado pôde indicar mais de uma resposta para esta questão, totalizando 18 incidências, conforme pode-se analisar na Tabela 3.

Tabela 3. Classificação dos motivos da busca pela profissionalização

\begin{tabular}{lr}
\hline \multicolumn{1}{c}{ Motivo da Procura } & Total de Alunos \\
\hline & --- \% ---- \\
Trabalha na área & 50,0 \\
Melhor classificação no mercado de & 27,8 \\
trabalho & 16,7 \\
Hobby & 5,5 \\
Facilidade na área & \\
\hline
\end{tabular}

Assim como os motivos da busca pela profissionalização, a evasão escolar pode ocorrer devido a vários elementos. Campos e Santana (2013) constataram que a evasão foi o resultado de muitos fatores, e os índices foram de corresponsabilidade da escola, família, sociedade e poder público. Essa reverberação resultou que a causa da evasão poderia ser dividida em dois fatores: internos e externos. $\mathrm{O}$ fator interno compreendeu a escola como corresponsável pelos motivos que levaram o aluno a evadir: dificuldade com conteúdo abordados; problemas com a didática do docente; conflito do período de início e término do curso em decorrência da escola realizar alterações em seu calendário; curso não satisfazia com aquilo que o aluno realmente precisava. $O$ fator externo entende que a escola não teve influência direta pelos motivos apresentados: a situação financeira; horário de trabalho incompatível com o curso; responsabilidades familiares, como gravidez própria ou de cônjuges; mudança de cidade; faixa salarial da categoria abaixo do desejado; o início de um curso no ensino superior.

Os fatores externos incidiram 13 vezes dentre os oito motivos apontados pelos alunos, destacando como maiores interferências na continuidade do curso o horário de trabalho incompatível, a mudança de endereço e as responsabilidades familiares (Figura 6). Com relação aos fatores internos, foram apresentadas três causas que influenciaram no abandono do curso, quais sejam, a alteração da programação do curso, dificuldades com a didática do docente e com os conteúdos abordados, esses fatores, juntos, foram apontados sete vezes como preponderantes ao abandono do curso.

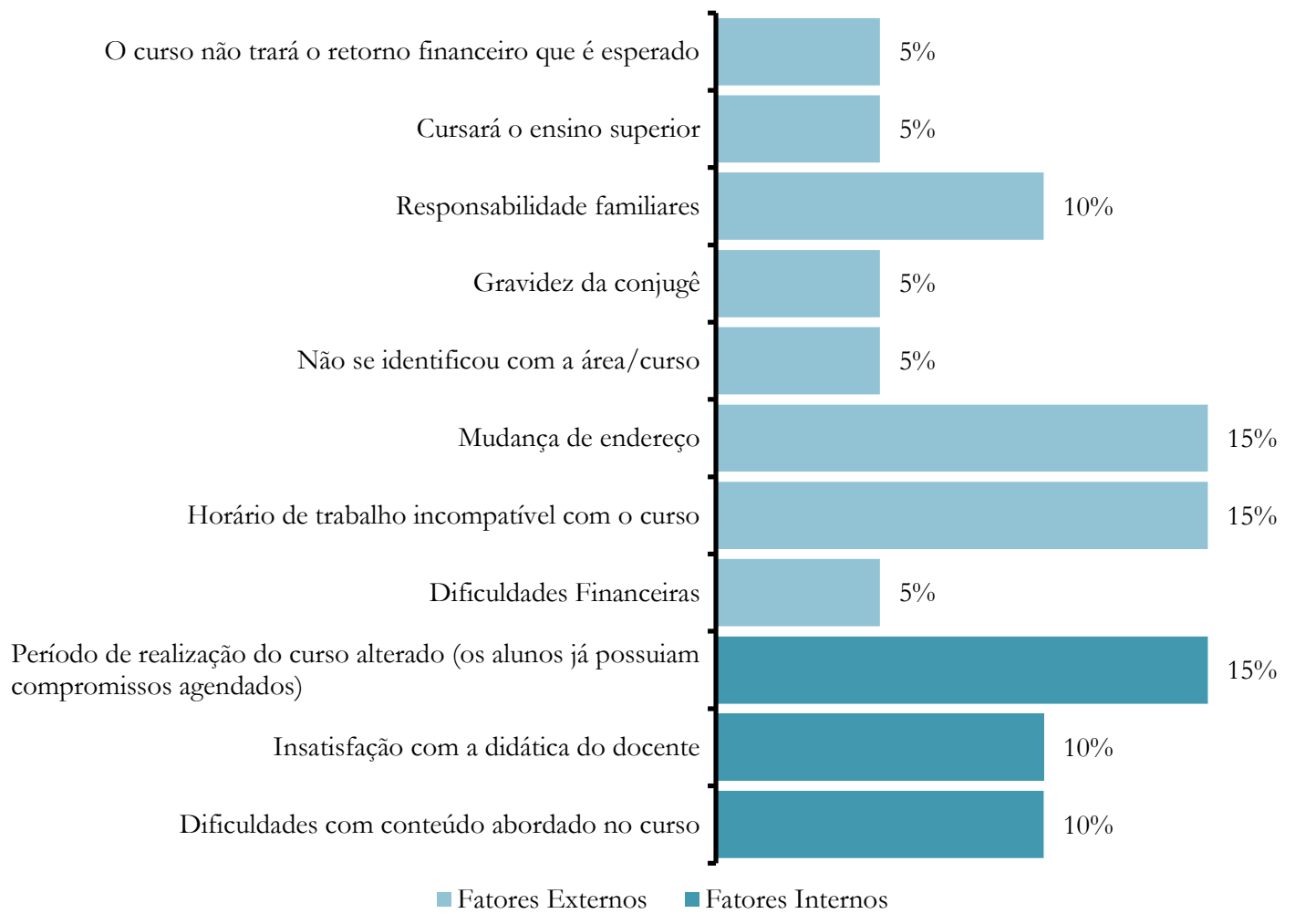

Figura 6. Classificação dos motivos da evasão 
A pesquisa ainda revelou que os alunos evadidos tiveram a expectativa atendida nos cursos que iniciaram e que 15 pretendiam retornar os estudos assim que possível. Os alunos evadidos, em sua totalidade, que participaram da entrevista, consideraram que o curso possui uma metodologia mais dinâmica no ensino, porém sem descartar aulas teóricas como ferramenta de ensino e que a elaboração de projetos que envolvem os alunos se sobressai em relação às provas teóricas.

Quando indagados se a instituição de ensino poderia realizar alguma ação para auxiliar na permanência no curso, oito alunos responderam que sim. Um dos alunos participantes da pesquisa relatou que a esposa estava grávida e precisaria interromper o curso para auxiliá-la durante e após a gravidez, porém acredita que a instituição poderia lançar meios para ajudá-lo a permanecer no curso (Participante A). Outro aluno evadido destacou que trancou o curso, pois estava com problemas financeiros e não havia conhecimento do processo de bolsa de estudos da instituição (Participante B).

Um dos alunos participantes da pesquisa ainda ressaltou que teve problemas no trabalho em grupo e que não houve mediação por parte do docente (Participante C). Outra resposta de um participante destacou o despreparo do professor que não sabe repassar o conhecimento, quando estava com dúvidas procurava por outros alunos, e sugere a troca de docentes (Participante F). Um participante considerou o curso de curta duração muito básico para o que necessita, porém cabe ressaltar que esse participante já havia sido orientado pela instituição a ingressar num outro curso com conhecimentos mais abrangentes e específicos da área, disponível na mesma unidade escolar. Houve ainda um participante que destacou que não terminou o curso por não ter conseguido se adaptar com a cidade (Participante D). Os alunos consideraram ainda que quando a instituição passa a ouvir o aluno, facilita muito sua permanência e estímulo à continuidade no curso.

\footnotetext{
A Evasão na Perspectiva dos Educadores e Gestores

Oíndice de evasão foi considerado alto, 39,2\%, (Tabela 1) na opinião de seis docentes, dos sete que responderam à pesquisa, e ressaltaram ser maior principalmente em cursos de longa duração, como níveis técnicos, que podem durar de um a dois anos e meio, diferentemente do que ocorre com as capacitações e cursos livres, que possuem, respectivamente, aproximadamente quatro meses e duas semanas de duração. A coordenação não opinou sobre o índice de evasão, porém também apontou que cursos de longa duração tendem a ter maior abandono por parte dos alunos. Em contrapartida, a supervisão considerou normais os índices apresentados.
}

Poucos alunos que almejaram o abandono do curso procuraram a equipe escolar para ter auxílio, conforme relato de três docentes, porém seis profissionais informaram que buscam realizar reflexões com os alunos que os procuram, ressaltando os benefícios que a conclusão do curso pode oferecer, e tentando entender os motivos do abandono, pois se esses forem de cunho pedagógico, os professores poderiam, segundo eles próprios, buscarem soluções por meio de ferramentas e metodologias diferenciadas.

Dentre os motivos da evasão apontados pelos alunos aos educadores, a situação financeira e escala de trabalho foram os maiores fatores que prejudicaram a permanência dos alunos nos cursos, porém não foram únicos agentes que os prejudicaram, segundo os docentes pesquisados. Três educadores consideraram que após o aluno conhecer a atuação profissional na qual o curso irá qualificá-lo, não se identifica e abandona-o. A coordenação complementa ainda que os alunos que em algum momento reprovaram ficam desestimulados e decidiram abandonar o curso. $\mathrm{O}$ fato apontado pela coordenação vai ao encontro do que indicaram Menezes e Santos (2001) ao afirmarem que a reprovação e a evasão são problemas que podem estar relacionados, uma vez que um dos fatores da evasão foi o desestímulo do aluno após sucessivas reprovações.

Houve também casos, como no programa menor aprendiz, em que o aluno foi contratado por uma empresa e parte das horas trabalhadas deve ser realizada na escola, capacitando para interação do prático e teórico. Estes alunos apresentaram dificuldades ou problemas com a empresa e considerou como a única forma de resolver o problema, o desligamento do programa.

\section{Planejamento: Necessidades dos Alunos ou da Escola?}

O Planejamento Escolar é uma ação a ser desenvolvida por todos os atores escolares - professores, coordenação, direção, funcionários, alunos e comunidade. Quando esse trabalho é feito de forma coletiva, as finalidades da escola seguem rumos profícuos, onde o foco é a produção do humano (Pimenta, 1993).

Dentre os docentes convidados a participar da pesquisa, dois foram consultados pela coordenação quando houve a realização do planejamento das ofertas de cursos. A aproximação que os professores possuem dos alunos pode ser enriquecedora para o desenvolvimento de ações e planejamentos e emancipação da escola, bem como a participação do próprio educando nesses momentos. Cravo (2012) destacou a importância do contato com o educando durante as ações de permanência do aluno realizada pela instituição até a conclusão do curso. 
A instituição não possui parceria ativa com empresas para a imersão dos alunos de cursos técnicos no mercado de trabalho. Todos os docentes entrevistados sinalizaram que costumam indicar vagas de estágios e efetivas aos alunos, para que se desenvolvam na área e ainda possam permanecer no curso. A coordenação indicou que há um mural de vagas disponível nas dependências, porém cabe à empresa procurar a escola para a divulgação e ao aluno verificar os murais e site da escola.

\section{Meios de Permanência do Aluno}

Promover a permanência do aluno e evitar o seu abandono do curso é uma ação necessária nas escolas, pois, para o sucesso das instituições de ensino, é fundamental a continuação e conclusão dos discentes nos cursos escolhidos e, para se ter esse resultado, a equipe deve criar meios e ações que efetivem a permanência do educando até o final do curso (Cravo, 2012). É essencial que a unidade escolar estabeleça vínculo com o educando por meio do diálogo; a escola deve ser receptiva aos sentimentos do aluno, entendendo seus motivos e suas expectativas estreitando as relações de confiança e fortalecendo o elo aluno-docente, dando real significado a palavra escola.

Esse vínculo com o aluno não deve ser apenas do docente ou da coordenação, todos os funcionários devem estar alinhados com as premissas escolares, serem receptivos aos problemas que o aluno carrega e que possam influenciar de maneira direta em seu desempenho escolar. Para Cravo (2012), os estudos sobre o abandono da escola não bastaram para efetivar a permanência do aluno na instituição, bem como contribuem para se conhecer as diversas dificuldades por trás da evasão, porém foi necessário traçar objetivos para lidar com os problemas, discutir e implementar dentro da escola a melhoria que se pode realizar e consequentemente estabilizar a permanência do aluno. Dessa maneira, a escola conseguirá diagnosticar e mapear os principais fatores que influenciam na escolha dos educandos a abandonarem o curso e a escola, possibilitando o retorno e a permanência efetiva dele até sua conclusão, por meio de soluções que devem ser desenvolvidas (Campos e Santana, 2013).

O início do curso é um momento que a escola pode realizar um acolhimento com os educandos, onde sejam compartilhadas tanto as expectativas dos alunos com relação ao curso e à escola, como a instituição possa esclarecer os objetivos da formação oferecida. Uma maneira que poderá ser eficaz no combate à evasão é trazer alunos egressos que possam demonstrar as dificuldades iniciais encontradas, além da apresentação do docente, contextualizando o que se pode esperar dos conteúdos e os benefícios que trouxe a conclusão do curso. A apresentação também deve ocorrer dos setores da instituição, o que cada um está lá fazendo por eles e caso precisem de alguma orientação, onde buscar.

A promoção de formação contínua dos docentes é essencial para acompanhar as mudanças que ocorre no mercado de trabalho, porém não deve ser restringido apenas na especialização da área que ministram o curso, é necessário também investir no desenvolvimento pedagógico, abordando as novas metodologias que podem ser aplicadas em aulas.

O aluno desmotivado também pode ser considerado um resultado do processo de educação formal, pois a não qualificação dos professores leva a uma aprendizagem deficitária (Cravo, 2012). Realizar, durante reuniões pedagógicas semanais, grupos de pesquisa e disseminação de novas ferramentas que podem ser aplicadas no processo ensino-aprendizagem - como problematização; uso de mecanismos de jogos para estimular o aprendizado na resolução de problemas, despertando curiosidade e vencendo desafios através do engajamento dos envolvidos (gamificação); incentivo a troca de experiências por intermédio de relatos; e, colocar em prática os estudos abordados para que o educando aprenda por meio da vivência - fortalecem o foco da escola nos educandos e em suas individualidades para que consigam acompanhar os conteúdos abordados. A fim de evitar a reprovação do aluno, uma vez que a escola é corresponsável quando se trata do não entendimento do aluno em relação aos assuntos estudados. O docente, em parceria com a coordenação, deve diagnosticar aqueles que não estão acompanhando e promover meios de recuperação contínuos, que intensifiquem a assimilação dos conteúdos abordados pelo aluno, não banalizando reprovações por falhas educacionais da instituição.

Como se constatou nesta pesquisa, problemas de ordem financeira puderam afligir alunos durante o curso, principalmente com a atual competitividade do mercado de trabalho (Figura 6). Para Campos e Santana (2013), o trabalho é uma necessidade de quem busca a capacitação profissional para inserção, recolocação e até mesmo ascensão no mercado, um fator externo difícil de ser resolvido, porém a escola pode criar ações e estratégias que garantam a permanência dos estudantes. Das ações que podem ser criadas, orientar o aluno que o mercado de trabalho seleciona aqueles que possuem maior preparo para as vagas; oferecimento de bolsas de estudos integrais, parciais, definitivas e temporárias -, orientação sobre os procedimentos e critérios de reparcelamento e financiamento das dívidas podem contribuir ativamente na permanência do aluno. Outra ação que pode ser estabelecida é realizar parcerias com empresas para realização de estágios na área, combatendo problemas financeiros e ainda aprofundando o conhecimento na prática profissional e inserindo o aluno no mercado de trabalho. 
As responsabilidades familiares, apontadas anteriormente (Figura 6) como fatores que levaram o aluno ao abandono da escola, é um contexto social que não é oriundo à escola, (Campos e Santana, 2013), pois o fator externo é difícil de ser resolvido no âmbito escolar, uma vez que foram relacionados a contextos sociais maiores. A escola não controla, mas pode se envolver junto ao aluno para discernir meios que sustentem a sua permanência. Gravidez e enfermidades possuem leis que orientam tratamentos excepcionais aos alunos (Brasil, 1969 e 1975, respectivamente). Em ambos os casos, a lei não prevê o mesmo tratamento quando o aluno é o acompanhante. Entretanto, devese levar em consideração que essas leis foram criadas durante o regime militar brasileiro, devendo ser readequadas à nova realidade. $\mathrm{O}$ Estatuto da Criança e do Adolescente [ECA] (Brasil, 1990) e o Estatuto do Idoso (Brasil, 2003) asseguram aos enfermos, quando menores de idade, idosos e as gestantes o acompanhamento de uma pessoa de sua confiança.

A flexibilização de horários dos cursos pelas instituições de ensino foi, também, uma forma de contribuir para a permanência do aluno e ainda tornar a escola acessível a quem precisar. O Artigo 4 da LDB assegura que o ensino deve estar adequado às necessidades do educando, garantindo, aos que forem trabalhadores, condições de acesso e permanência (Brasil, 1996). Para isso, um estudo com os alunos e comunidade local atendida foi vital para que a ação seja bem-sucedida, mapeando, por cada área do curso, a jornada e escala de trabalho do público atendido, e das empresas locais que contrataram os profissionais, levando em consideração, também, o percurso realizado pelos alunos até a instituição. A programação de férias também pode ser realizada junto aos alunos. A instituição de ensino pesquisada possui um recesso das festas de final de ano, retornando as aulas de todos os cursos na segunda semana de janeiro, porém o que não foi avaliado se os alunos que utilizaram transportes fretados que funcionaram no período mencionado, ou se as empresas de transportes públicos ofereceram o benefício durante esse interregno.

Promover meios que facilitem a permanência do aluno na escola não é um processo fácil, porém a escola só faz sentido com alunos. Atualizar as práticas pedagógicas de forma atrativa, acompanhar as tendências do mercado de trabalho e realizar parcerias ativas, estreitar relacionamentos com o aluno realizando um acompanhamento pedagógico e reuniões de alinhamento das equipes para que todos tenham a mesma comunicação e perfil mediador, com foco no aluno são atitudes sociais que favorecem a intenção de formar profissionais para o mercado de trabalho.

\section{Considerações Finais}

De acordo com os dados coletados, o público feminino representa $66,5 \%$ das matrículas em cursos profissionais, porém os resultados de evasão e desistência desses cursos são semelhantes, em relação à proporção, sendo de $51,7 \%$ de abandono do sexo masculino e 51,3\% do sexo feminino. Ainda na análise dos dados coletados, das turmas encerradas apenas $37,4 \%$ dos educandos concluíram o curso com aprovação.

Os resultados da pesquisa mostram que há mais fatores externos que influenciam na evasão, destacando-se a jornada laboral e mudança de endereço que interferiram mais, do que aqueles ditos internos, onde alterações no período de programação do curso e dificuldades com didática e conteúdos abordados foram apresentadas como principais motivos que influenciam na desistência do aluno. Ainda que esses fatores não sejam oriundos da escola, cabe promover um ambiente sólido e facilitador, que garanta a permanência do educando.

Uma das ferramentas primordiais para essa promoção é o Projeto Político Pedagógico, pois ao ser construído coletivamente suas responsabilidades são compartilhadas, e seu foco torna-se significativo a todos - Educadores, educandos, e agentes de apoio à concretização das premissas escolares. Assim, o gestor deve ter em mente que o PPP não deve ser um simples documento que deve permanecer arquivado e de perfil regulatório, ele deve ganhar vida, retratando a escola e refletindo seus objetivos, dentro de um ambiente de compartilhamento, formativo, construtivo e horizontalizando as relações institucionais, enfim, emancipando-a.

Neste sentido, para evitar a evasão, foram propostos meios que a escola pode atuar, por intermédio de seu PPP, para favorecer a permanência dos alunos e até mesmo realizar o resgate dos que já evadiram. Realizar ações de acolhimento, apresentando o curso e a escola - tanto sua estrutura física quanto seus objetivos como instituição formadora - onde o aluno possa compreender e estabelecer as expectativas, conhecendo as atribuições que poderá exercer com sua formação; capacitar continuamente os educadores e instituir metodologias atrativas aos alunos, que facilitem o entendimento dos conteúdos abordados, por mais difíceis que sejam, para que todos os educandos sejam contemplados e beneficiados com a proposta do curso; abrir as portas do mercado de trabalho por meio de parcerias com empresas que contrate por intermédio de estágios e outros vínculos empregatícios, bem como analisar individualmente a situação do educando que necessite de bolsa de estudos são ações que podem combater o abandono originário de problemas financeiros; flexibilizar os horários dos cursos ofertados, de acordo com a necessidade do aluno. Para a concretização das ações a escola - docentes, coordenação e demais agentes escolares - devem criar vínculos com 
os educandos, onde por meio do diálogo será possível identificar o problema e pensar na ação mais adequada para favorecer a permanência do aluno e dessa forma consolidar os objetivos de formação do PPP.

Desse modo, conclui-se que burocratizar os processos, engessar as ofertas dos cursos e realizar o planejamento sem dar voz aos principais atores da educação - educandos, foco principal da escola, e educadores, que com sua aproximação sabem e sentem as dificuldades do aluno - faz com que a escola não seja inclusiva. Recusando, veladamente, os que realmente necessitam dela para mudar suas perspectivas, melhorar sua qualificação e ainda mudar seu contexto social. Priorizar as necessidades dos alunos no âmbito escolar garante que as instituições de ensino cumpram com seus objetivos de formação profissional e cidadã, fortalece a permanência do aluno e abre as portas do mercado de trabalho.

Em suma, para promover meios que facilitem a permanência do aluno na escola deve-se haver uma reflexão coletiva dentro das dependências do colégio, dos papéis de todos os profissionais envolvidos, priorizando o diálogo e estreitamento das relações escolares, trabalhando como pares, assim fortalecendo as práticas pedagógicas de todos os envolvidos no processo de ensino aprendizagem e planejando coletivamente as ações e expectativas da instituição de ensino.

\section{Referências}

Brasil. 1969. Lei n. 1044, de 21 de outubro de 1969. Dispõe sobre tratamento excepcional para os alunos portadores das afecções que indica. Disponível em: <http://www.planalto. gov.br/ccivil_03/decreto-lei/Del1044.htm>. Acesso em: 24 fev. 2018.

Brasil. 1975. Lei n. 6202, de 17 de abril de 1975. Atribui à estudante em estado de gestação o regime de exercícios domiciliares instituído pelo Decreto-lei n. 1044, de 1969, e dá outras providências. Disponível em: < http://www.planalto. gov.br/ccivil_03/leis/1970-1979/16202.htm>. Acesso em: 24 fev. 2018.

Brasil. 1990. Lei n. 8069, de 13 de julho de 1990. Dispões sobre o Estatuto da Criança e do Adolescente e dá outras providências. Disponível em: <http://www.planalto.gov.br/ ccivil_03/leis/18069.htm>. Acesso em: 2 fev. 2018.

Brasil. 1996. Lei n. 9394, de 20 de dezembro de 1996. Estabelece as diretrizes e bases da educação nacional. Disponível em: <http://www.planalto.gov.br/Ccivil_03/leis/L9394.htm>. Acesso em: 3 dez. 2017.

Brasil. 2003. Lei n. 10741, de $1^{\circ}$ de outubro de 2003. Dispõe sobre o Estatuto do Idoso e dá outras providências. Disponível em: <http://www.planalto.gov.br/ccivil_03/ leis/2003/110.741.htm>. Acesso em: 2 fev. 2018.

Campos, R.K.N.; Santana, G.C. 2013. Fatores e motivos da evasão escolar no curso técnico subsequente de manutenção e suporte em informática do IFS - Campus Itabaiana. In: XI Congresso Nacional de Educação - Educere, 2013, Curitiba, PR, Brasil. 3260-3270. Disponível em: < http://educere.bruc. com.br/arquivo/pdf2013/8938_5032.pdf>. Acesso em: 5 dez. 2017.

Cravo, A.C. 2012. Análise das causas da evasão escolar do curso técnico de informática em uma faculdade de tecnologia de Florianópolis. Revista GUAL 5(5): 238-250.

Gerhardt, T.E.; Silveira, D.T. (orgs). 2009. Métodos de pesquisa. Editora da UFRGS, Porto Alegre, RS, Brasil.

Meira, C.A. 2015. A evasão escolar no ensino técnico profissionalizante: um estudo de caso no campus Cariacica do Instituto Federal do Espírito Santo. Centro de Ciências Jurídicas e Econômicas, Universidade Federal do Espírito Santo, Vitória, ES, Brasil. Disponível em: <http://portais4. ufes.br/posgrad/teses/tese_9068_Disserta $\%$ E7\%E30\%20 Final $\% 20-\% 20$ Cristiane $\% 20$ Meira.pdf $>$. Acesso em 31 mar. 2018.

Menezes, E.T.; Santos, T.H. 2001. Verbete evasão escolar. Dicionário Interativo da Educação Brasileira - Educabrasil. São Paulo: Midiamix, 2001. Disponível em: <http://www. educabrasil.com.br/evasao-escolar/>. Acesso em: 25 jan. 2018.

Pimenta, S.G. 1993. Questões sobre a organização do trabalho na escola. Ideias 16: 78-83.

Queiroz, L.D. 2002. Um estudo sobre a evasão escolar: Para se pensar a inclusão social. In: $25^{a}$ Reunião anual da Anped 1: 1-18. Disponível em: <http://www.seduc.go.gov.br/ imprensa/documentos/Arquivos/15\%20-\%20Manual $\% 20$ de $\% 20$ Gest $\%$ C3\%A3o $\% 20$ Pedag $\%$ C3 $\%$ B3 gico $\% 20$ e $\% 20$ Administrativo $/ 2.10 \% 20$ Combate $\% 20 \% \mathrm{C} 3 \% \mathrm{~A} 0 \% 20$ evas $\% \mathrm{C} 3 \% \mathrm{~A} 3 \mathrm{o} / \mathrm{UM} \% 20 \mathrm{ESTUDO} \% 20 \mathrm{SOBRE} \% 20 \mathrm{~A} \% 20$ EVAS $\%$ C3\%83O\%20ESCOLAR $\% 20$ - \%20PARA $\% 20$ PENSAR \%20NA\%20EVAS\%C3\%83O\%20ESCOLAR. pdf>. Acesso em 8 fev. 2018.

Veiga, I.P.A. 2011. Projeto político-pedagógico da escola: uma construção coletiva. p. 11-35. In: Santiago, A. R. F.; Bussmann, A. C.; Neves, C. M. C.; Falkembach, E. M. F.; Veiga, I. P. A.; Resende, L. M. G.; Marques, M. O.; Zasso, S. M. B. Projeto político-pedagógico da escola: uma construção possível. 29. Papirus, Campinas, SP, Brasil.

Vieira, A.B.D.P; Souza Junior, A. 2016. A Educação Profissional no Brasil. Interacções 12(40): 152-169. Disponível em: $\quad<$ http://revistas.rcaap.pt/interaccoes/article/ viewFile/10691/7655>. Acesso em: 26 jul. 2018. 